\title{
Correspondence
}

\section{Anterior epidural haematoma following subarachnoid block}

To the Editor:

We have observed an epidural haematoma (EH) in a 64-yr-old female patient admitted for a right-knee fracture. At admission she was not receiving any medication. There was a remote history, $17 \mathrm{yr}$ earlier of possible primary biliary cirrhosis. The only abnormal tests were the serum alkaline phosphatase (ALP) (407 U $\cdot \mathrm{L}^{-1}$ ) and serum gamma-glutamyl transpeptidase (GGT) $\left(168 \mathrm{U} \cdot \mathrm{L}^{-1}\right)$. Prophylaxis against deep venous thrombosis was undertaken with $5000 \mathrm{U}$ calcium heparinate $s c$ every eight hours. Coagulation status, monitored at the time of surgery, showed platelet count $128.000 \cdot \mathrm{ml}^{-1}$, fibrinogen 397 $\mathrm{mg} \cdot \mathrm{dl}^{-1}$, prothrombin time $100 \%$, and activated partial thromboplastin time $30 \mathrm{sec}$. Spinal anaesthesia was performed $16 \mathrm{hr}$ after the last dose of heparin using a 25-ga Quincke spinal needle at $\mathrm{L}_{3-4}$. Needle placement was easy and free flow of unstained cerebrospinal fluid was obtained at the first attempt. Postoperative medications included diclofenac sodium $75 \mathrm{mg}$ im administered once.

Two days later, a magnetic resonance imaging (MRI) (required due to the appearance of paraesthesiae, perineal numbness and lower extremity weakness) showed an anterior extradural haematoma from $\mathrm{L}_{2}$ to $\mathrm{L}_{4}$ (Figure). Laminectomy was performed and a non organized haematoma was drained. One month after surgery the patient was able to walk with the aid of a cane and her bladder paresis was recovering. The EH was located in front of the spinal cord and this uncommon site for EH may be linked to the small bore of the spinal needle employed. The lack of feeling during needle placement and the long delay before CSF appeared at the hub may have been the cause of unrecognized dislocation of the needle tip in the anterior area of epidural space.

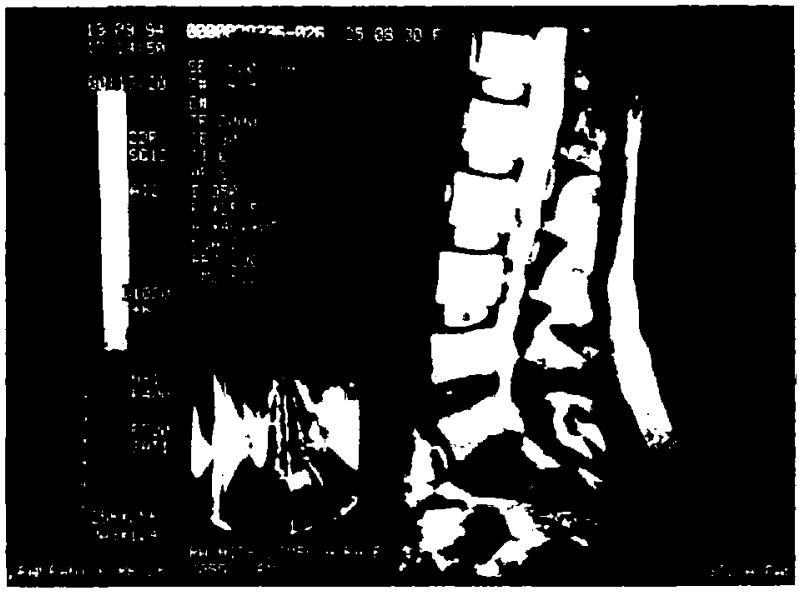

FIGURE MRI scan: Fusijam swelling anterior to the cord.
A crucial role in spinal bleeding might be attributed to the use of subcutaneous heparin ${ }^{1.2}$ but other factors in this patient may have contributed and spontaneous bleeding is not excluded. An increase of portal pressure, which may occur with hepatic dysfuntion, may divert blood into epidural veins, which become dilated and prone to bleeding. ${ }^{3}$ Although the platelet count was within the normal range, we do not know how well those platelets were functioning and what effect liver disease might have on platelet function. Finally, the association between heparin and NSAIDs is considered as a risk factor of bleeding following central neuraxial blockade. ${ }^{4}$

\section{F. Bartoli MD \\ R. Barbagli MD}

F. Rucci PhD

Servizio di Anestesia e Rianimazione

Centro Traumatologico Ortopedico

Largo Palagi 1, 50139 Firenze, Italy

\section{REFERENCES}

1 Janis KM. Epidural hematoma following postoperative epidural analgesia: a case report. Anesth Analg 1972; 51 689-92.

2 Varkey $G P$, Brindle $G F$. Peridural anaesthesia and anticoagulant therapy. Can Anaesth Soc J 1974; $21: 106-9$

3 Dunn D, Dhopesh V, Mobini J. Spinal subdural hematoma: a possible hazard of lumbar puncture in an alcoholic. JAMA 1979; 241: 1712-3.

4 Owens EL, Kasten GW, Hessel EA 2nd. Spinal subarachnoid hematoma after lumbar puncture and heparinization a case report, review of the literature, and discussion of anesthetic implications. Anesth Analg 1986; 65: 1201-7.

\section{Acute transient unilateral macroglossia following use of a LMA}

To the Editor:

Postoperative complications involving the tongue are uncommon following use of the LMA. Pressure from the LMA cuff at the base of the tongue may occasionally cause neurapraxia of the hypoglossal nerve $e^{1,2}$ where the nerve, accompanied by the lingual vein, passes between the hypoglossus muscle and the hyoid bone. ${ }^{3}$ We report a case of transient postoperative unilateral macroglossia without nerve deficit following uneventful use of a laryngeal mask airway for a 30 min surgical procedure.

\section{Case history}

A 66-yr-old man weighing $70 \mathrm{~kg}$ with carcinoma of the prostate was admitted to hospital for urological investigation. His current medications were enteric-coated aspirin, lisinopril, amoxicillin, and ciprofloxacin. He underwent a cystoscopy under general anaesthesia with propofol, fentanyl, nitrous oxide and isoflurane plus prophylactic gentamycin and ampi- 
cillin. A sizc 3 LMA, lubricated with Muko® (propylene glycol, hydroxyethyl cellulose, methyl and propyl paraben and water), was inserted easily at the first attempt and was removed after $35 \mathrm{~min}$. His recovery and postoperative course were uneventful. Five days later, he underwent a needle biopsy of the prostate and anal sphincter dilatation under general anacsthesia with the same anaesthetic agents and prophylactic antibiotics. A size 4 LMA, lubricated as before, was inserted easily at the first attempt and its cuff inflated with $30 \mathrm{ml}$ room air. It was removed at the end of the 30 minute procedure at 1300. The patient awoke uneventfully in recovery room and was discharged to his room. At approximately 1515 he noticed progressive swelling of the right side of his neck and the right side of his tongue that had not been present when he first awoke. There was no pain or numbness and no symptoms or signs of respiratory obstruction developed at any time. The tongue protuded centrally but its swelling made speech difficult and two small blisters were observed on the right inferior surface. Diphenhydramine $50 \mathrm{mg} i v$ was given without benefit. The bulk of the tongue made swallowing difficult but he could still eat and drink. Shortly before midnight the swelling began to resolve spontaneously. By the following morning the neck swelling had disappeared completely. There was still minimal residual swelling of the right side of the tongue with redness on its inferior surface, and speech and swallowing were normal. Ultrasound examination of the neck showed no evidence of venous occlusion of the lingual vein or the internal jugular vein. Further recovery was uneventful.

The swelling of the right side of the tongue and neck in this patient occurred two hours after a brief, uneventful anaesthetic. Possible causes include an allergic reaction or angioneurotic oedema, damage to the right hypoglossal nerve, or obstruction to venous return. The most likely explanation appears to be pressure-induced venous thrombosis, although the LMA was inserted easily and atraumatically, it was clinically in good position, the black line was central against the upper gum, and the weight of the lightweight breathing circuit was taken by a tube support (Anesthesia Associates, Inc., San Marcos CA.). We have been unable to find reference to similar transicnt postoperative tongue swelling through a Medline ${ }^{\circledR}$ search or in textbooks of otolaryngology and oral surgery and would appreciate comments from readers.

J. Roger Maltby MB FRCA FRCPC

Tom Elwood MD

Brian Price $M D$

Department of Anaesthesia

Foothills Hospital

140329 Street NW

Calgary, AB T2N 2T9

\section{REFERENCES}

I Nagai K, Sakuramoto C, Goto $F$. Unilateral hypoglossal nerve paralysis following the use of the laryngeal mask airway. Anesthesia 1994; 49: 603-4.

2 King C, Street $M K$. Twelfth cranial nerve paralysis following use of a laryngeal mask airway. Anaesthesia 1994; 49: 786-7.

3 Ballenger. $/ J$. Anatomy of the oral cavity and pharynx: physiological and surgical aspects. In: Ballenger JJ (Ed.). Diseases of the Nose, Throat, Ear, Head, and Neck. London: Lea \& Febiger, 199l: 259-7l.

\section{A combination of low dose spinal and general anaesthesia for laparoscopic cholecystectomy}

To the Editor:

We wish to comment on the recent report on the benelicial effect of coadministration of general and spinal anaesthesia (GSA) for coronary artery bypass surgery.' After institutional approval and informed consent we conducted a similar study for laparoscopic cholecystectomy (LC) in 28 patients randomized into two groups. Group 1 or GSA group and Group 2, or general anaesthesia $(\mathrm{GA})$. Both groups received a standardized general anaesthetic protocol consisting of fentanyl, etomidate, isoflurane, and rocuronium. To achieve $T_{4-5}$ level on the right side patients in Group 1 were placed in a left flexed decubitus position in $20^{\circ}$ reversed Trendelenburg. Then hypobaric solution of pontocaine $0.2 \%\left(0.1 \mathrm{mg} \cdot \mathrm{kg}^{-1}\right)$ and $25 \mu \mathrm{g}$ fentanyl were administered intrathecally by $25-G$ spinal needle ${ }^{2}$ and GA was induced.

Our data revealed an absence of nausea and a large reduction $(66 \%)$ of postoperative analgetic consumption in the GSA group. Function of diaphragm 2 and $24 \mathrm{hr}$ postoperatively was preserved in Group 1 compared with Group 2 where noticeable reduction of sustained maximum inspiration $(-23+4 \%)$ was observed ${ }^{3}$. No problems were associated with the subarachnoid injection. For the last three years the combined pontocaine/morphine GSA technique was also used in 47 cases of major abdominal procedures. It appears that the described technique offers effective analgesia well into postoperative period, preserves the function of diaphragm, and allows earlier extubation.

Simon Gurmarnik MD

Marquerritte Poreda MD

Department of Anesthesia

Gerald M. Reid MD

John T. Frasca MD

Raymond Paul-Blanc MD

Department of Surgery

Southwood Community Hospital

111 Dedham St., Norfolk MA 02056

REFERENCES

1 Kowalewski RJ, MacAdams CL, Eagle CJ, Archer DP. $B$ haradwaj $B$. Anaesthesia for coronary artery bypass surgery supplemented with subarachnoid bupivacaine and morphine: a report of 18 cases. Can J Anaesth 1994; 41 : 1189-95.

2 Lund PC, Rumball AC. Hypobaric pontocaine spinal anesthesia - 1640 consecutive cases. Anesthesiology 1947; 8: 181-99.

3 Erice F, Fox GS, Salib YM, Romano E, Meakins $J L$, Magder SA. Diaphragmatic function before and after laparoscopic cholecystectomy. Anesthesiology 1993; 79: 966-75. 